\title{
Clinical results of the application of the transarticular fixation technique with the use of the device for the exact spokes conduction for fractures of the ankles with foot dislocation
}

\author{
${ }^{\prime}$ Emergency Medical Care Department, Semey Medical \\ University, Semey, Republic of Kazakhstan \\ ${ }^{2}$ General Medicine Faculty, Semey Medical University, \\ Semey, Republic of Kazakhstan
}

Askar Serikbaev $^{1}$, Almas Dyusupov ${ }^{1}$, Asanali Seitkabylov

Abstract
This work is licensed under a

Creative Commons Attribution 4.0

International License

\section{Received: 2018-05-03}

Accepted: 2018-06-21

UDC: 616.1

\section{J CLIN MED KAZ 2018;2(48):47-51}

Corresponding author:Askar Serikbaev, Semey State Medical University. Postal address: 9/1, Shmidt Street, ap. 84, Semey, Republic of Kazakhstan.

Tel.: +7 7554012011

E-mail: askar.s_79@mail.ru
Objective: To determine the comparative clinical outcomes and quality of life of patients with ankle fractures with dislocation of the foot using the transarticular fixation technique.

Material and methods: 232 patients with closed fractures of the ankles, accompanied by subluxation or dislocation of the foot at the age of 19 to 75 years (mean age $-45.6 \pm 2.4$ years) were examined. The subjects were divided into 2 groups - the main group (142 patients - 61.2\%) and comparisons (90 - 38.8\%). In the treatment of patients of the main group, the method of transarticular fixation of the foot to the tibia was used, using a device specially developed for this purpose. The patients of the comparison group underwent an operation of open osteosynthesis with knife plates with screws or a wire loop.

Comparison of clinical indices, functional outcomes and quality of life was performed using the FOAS technique.

Results: The average for the main group of complications was $11.3 \%$, for the comparison group $-35.6 \%(\chi 2=19.80, p=0.002)$. The use of the technique of transarticular fixation contributed to a decrease in the treatment period by 8.6 days $(p>0.05)$. Excellent functional results were obtained in the main group by $25.4 \%$ more often, although the differences were insignificant. Unsatisfactory results were observed only in the comparison group. Significant differences in quality of life in favor of the main group were determined on the basis of the "pain" scale of the FOAS questionnaire at a 6-month follow-up period (46.7\%, $\mathrm{p}<0.05)$. On the scale of "sports and recreation" similar differences were revealed in the period of 6 and 9 months.

Conclusion: The use of the transarticular fixation method in our study turned out to be expedient and gave better results than open interventions with respect to the clinical course and the quality of life of patients.

Key words: fractures of the ankles, dislocation of the foot, transarticular fixation, functional results, the quality of life

ТОБЫҚ СЫНЫҒЫ КЕЗІНДЕГІ БІЗДІН ТУРА ӨТКІЗІЛУІ ҮШІН ҚҰРЫЛҒЫ КӨМЕГІМЕН ТРАНСАРТИКУЛЯРЛЫ ФИКСАЦИЯ ӘДІСІН ҚОЛДАНУДЫН НӘТИЖЕЛЕРІ

Серикбаев А.С. ${ }^{1}$, Дюсупов А.А. ${ }^{1}$, Сеиткабылов А.А. ${ }^{2}$

'Жедел медициналық жәрдем кафедрасы, Семей Мемлекеттік Медицина Университеті, Семей, Қазақстан Республикасы

²Жалпы медицина факультеты, Семей Мемлекеттік Медицина Университеті, Семей, Қазақстан Республикасы

\section{ТҰЖЫРЫМДАМА}

Мақсаты: Тобықтың сынуымен қатар жүретін табан таюы бар, құрылғыны колдану арқылы трансартикулярлы фриксация тәсілімен емделген науқастардың өмір сапасын және салыстырмалы клиникалық нәтижелерді анықтау.

Материалдар мен әдістер: Тобықтың жабық сынуымен қатар жүретін табан таюы немесе таиқуымен 19-75 жас (ораташа жас-

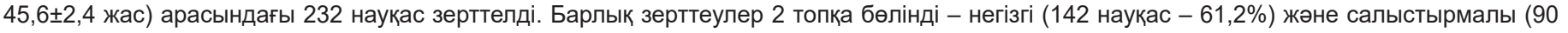
- 38,8\%). Негізгі топтағы науқастардың емінде табанды асықты жілікке трансартикулярлы бекітуге арнайы осы мақсатта жасалған құрылғы қолданылған. Салыстырмалы топтағы науқастардың емінде сүйек үсті пластинасы, винттер немесе сым ілмегімен ашық остеосинтез операциясы жүргізілді.

FOAS тәсілінің қолданылуымен функционалды нәтиже және өмір сапасы, клиникалық көрсеткіштер салыстыруы жүргізілді. 
Нәтижелері: Орташа есеппен, негізгі топта асқыну 11,3\% құрады, салыстырмалы топта - 35,6\% (х2=19.80 p=0.002). Трансартикулярлы фиксация әдісін қолдану емделу ұзақтығын 8,6 тәулікке азайтты (р>0.05). Айырмашылықтар көп болмағанымен, жақсы фунционалды нәтижелер негізгі топта 25,4\% жиі анықталды. Қанағаттанарлықсыз нәтижелер тек салыстыру тобында байқалды. 6 ай мерзімінде FOAS сауалнама көмегімен зерттеу ішінде «ауырсыну» шкаласынан мәнді айырмашылықтар алынды - өмір сапасы жағынан негізгі топта басым (46,7\%, p<0,05). «Спорт және демалыс» шкаласы бойынша 6 және 9 ай мерзімінде ұқсас өзгерістер анықталды.

Қорытынды: Науқастардың өмір сапасы, клиникалық ағымы жағынан да біздің зерттеудегі трансартикулярлы фриксация әдісін қолдану, ашық араласуларға қарағанда қолданылуы жөнді және жақсы нәтиже берді.

Кілтті сөздер: тобық сынығы, табанның таюы, трансартикулярлы фиксациясы, функциональды нәтижелер, өмір сапасы

\section{КЛИНИЧЕСКИЕ РЕЗУЛЬТАТЫ ПРИМЕНЕНИЯ МЕТОДИКИ ТРАНСАРТИКУЛЯРНОЙ ФИКСАЦИИ С ПРИМЕНЕНИЕМ АППАРАТА ДЛЯ ТОЧНОГО ПРОВЕДЕНИЯ СПИЦ ПРИ ПЕРЕЛОМАХ ЛОДЫЖЕК С ВЫВИХОМ СТОПЫ}

А.С. Серикбаев ${ }^{1}$, А.А. Дюсупов ${ }^{1}$, А.А. Сеиткабылов ${ }^{2}$

'Кафедра скорой медицинской помощи, Государственный медицинский университет г.Семей, Семей, Республика Казахстан

${ }^{2}$ Общемедицинский факультет, Государственный медицинский университет г.Семей, Семей, Республика Казахстан

\section{PE3ЮME}

Цель: Определение сравнительных клинических результатов и качества жизни больных с переломами лодыжек с вывихом стопы при использовании методики трансартикулярной фиксации.

Материалы и методы: Обследовано 232 пациента с закрытыми переломами лодыжек, сопровождающимися подвывихом или вывихом

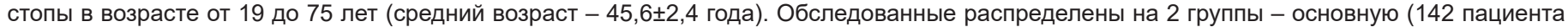
- 61,2\%) и сравнения (90 - 38,8\%). В лечении пациентов основной группы был использован метод трансартикулярной фриксации стопы к большеберцовой кости с применением специально разработанного с этой целью устройства. У больных группы сравнения проводилась операция открытого остеосинтеза накостными пластинами с винтами или проволочной петлей.

Осуществлено сравнение клинических показателей, функциональных исходов и качества жизни с использованием методики FOAS.

Результаты: В среднем по основной группе частота осложнений составила 11,3\%, по группе сравнения - 35,6\% (х2=19,80, p=0,002). Применение методики трансартикулярной фиксации способствовало уменьшению периода лечения на 8,6 суток (р>0,05). Отличные функциональные результаты были получены в основной группе на 25,4\% чаще, хотя различия были незначимыми. Неудовлетворительные результаты наблюдались только в группе сравнения. Значимые различия по качеству жизни в пользу основной группы определены по шкале «боль» опросника FOAS в срок обследования 6 месяцев $(46,7 \%$, р<0,05). По шкале «спорт и отдых» аналогичные различия выявлены в срок 6 и 9 месяцев.

Вывод: Использование способа трансартикулярной фиксации в нашем исследовании оказалось целесообразным и дало лучшие результаты, чем открытые вмешательства как в отношении клинического течения, так и качества жизни пациентов.

Ключевые слова: переломы лодыжек, вывих стопы, трансартикулярная фриксация, функциональные результаты, качество жизни

\section{Введение}

В лечении пациентов с переломами конечностей в настоящее время используются два основных подхода - оперативный (открытый) остеосинтез и чрескостный (закрытый) остеосинтез [1,2]. Оба этих подхода имеют свои достоинства и недостатки, своих сторонников среди врачей и исследователей. При одних и тех же переломах отломки могут быть фиксированы различными способами в зависимости от возможностей клиники и предпочтений специалистов $[3,4]$.

Развитие обоих направлений происходит параллельно, и нельзя утверждать, что лучшие клинические результаты могут быть достигнуты только на одном из путей.

В круг задач, стоящих перед травматологом, входит обеспечение полной репозиции и устойчивой фиксации отломков до сращения при возможно меньшей вторичной травматизации области повреждения, профилактика осложнений, обеспечение возможно более ранней и полной активизации пациента. Все эти требования в значительной степени противоречат друг другу, что вызывает необходимость дальнейшего развития основных методов лечения [1,5].

Переломы лодыжек с вывихом стопы остаются одними из относительно сложных для лечения повреждений, в значительной части случаев дающих осложнений и недостаточные функциональные результаты [6,7]. Это является основанием для проведения настоящего исследования.

\section{Цель работы}

Определение сравнительных клинических результатов и качества жизни больных с переломами лодыжек с вывихом стопы при использовании методики трансартикулярной фиксации.

\section{Материалы и методы}

Обследовано 232 пациента с закрытыми переломами лодыжек, сопровождающимися подвывихом или вывихом стопы, в том числе 145 мужчин $(62,5 \%)$ и 87 женщин $(37,5 \%)$ в

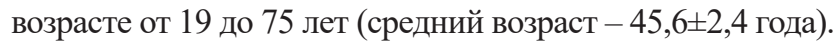

Все обследованные были распределены на 2 группы - основную и сравнения. В основную группу включены 142 пациента (61,2\%), в группу сравнения - 90 (38,8\%).

Распределение больных в зависимости от клинической группы и вариантов повреждения, выделенных по классификации АО, представлено в Таблице 1.

Таблища 1 Распределение больных по группам и характеру перелома

\begin{tabular}{|c|c|c|c|c|}
\hline \multirow{3}{*}{ Характер перелома } & \multicolumn{4}{|c|}{ Группы } \\
\hline & \multicolumn{2}{|c|}{ основная } & \multicolumn{2}{|c|}{ сравнения } \\
\hline & абс. число & $\%$ & абс. число & $\%$ \\
\hline A3 & 8 & 5,6 & 7 & 7,8 \\
\hline B1 & 18 & 12,7 & 9 & 10,0 \\
\hline B2 & 30 & 21,1 & 18 & 20,0 \\
\hline B3 & 37 & 26,1 & 30 & 33,3 \\
\hline $\mathrm{C} 1$ & 19 & 13,4 & 9 & 10,0 \\
\hline $\mathrm{C} 2$ & 18 & 12,7 & 10 & 11,1 \\
\hline $\mathrm{C} 3$ & 12 & 8,5 & 7 & 7,8 \\
\hline Итого & 142 & 100 & 90 & 100 \\
\hline
\end{tabular}


Наиболее часто в структуре повреждений наблюдались типы В2 (перелом на уровне синдесмоза с медиальным повреждением) и В3 (перелом на уровне синдесмоза с медиальным повреждением и переломом заднелатерального края).

В лечении пациентов основной группы был использован метод трансартикулярной фиксации стопы к большеберцовой кости с применением специально разработанного с этой целью устройства.

У больных группы сравнения проводилась операция открытого остеосинтеза накостными пластинами с винтами или проволочной петлей.

Осуществлялась оценка течения раннего (стационарного) и отдаленного (амбулаторного) периодов лечения пациентов обеих групп с учетом частоты и структуры осложнений, продолжительности лечения и его функциональных исходов.

Исследование качества жизни осуществлялось путем анкетирования пациентов по методике FOAS (Foot and Ankle Outcome Score - специализированный опросник русифицированный адаптированный на кафедре МГМСУ) [8]. Применение опросника FOAS проводилось в динамике, в сроки $1,3,6,9$ и 12 месяцев.

Статистическийанализпроводилсявспециализированном программном продукте SPSS Statistica 20.0. Анализ частотных показателей проведен с использованием критерия ұ2 Пирсона и точного критерия Фишера (при n $<10$ в любой из выделенных подгрупп).

Анализ непрерывных показателей проводился с использованием параметрических (критерий $\mathrm{t}$ Стьюдента) и непараметрических (критерий Манна-Уитни) методов при неприменимости t-критерия по причине отсутствия нормального распределения вариационного ряда.

Граничным уровнем статистической значимости для опровержения нулевой гипотезы принимали $\mathrm{p}<0,05$.

\section{Результаты исследования}

На Рисунке 1 представлены сравнительные данные о частоте развития различных осложнений остеосинтеза в группах обследованных.

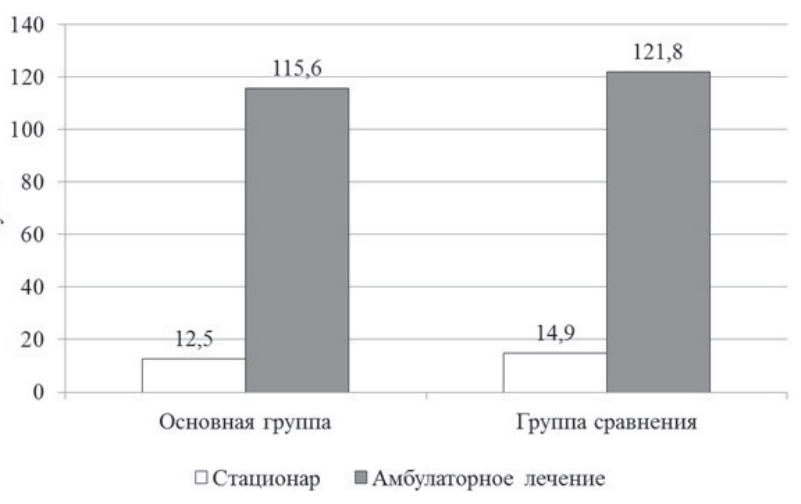

Рисунок 1 - Частота осложнений лечения больных основной группы и группы сравнения

Частота большинства осложнений в группах обследованных была вполне сравнимой. Вторичное смещение отломков было относительно нечастым и развилось в 4,9\% случаев и основной группе и 5,6\% - в группе сравнения $(\mathrm{p}>0,1)$. Глубокое нагноение раны и краевой некроз кожи были характерны только для открытого способа лечения, их совокупная частота составила 14,4\%. Несколько (незначимо) чаще в группе сравнения наблюдалась контрактура суставов и замедленная консолидация.
В среднем по основной группе частота осложнений составила 11,3\% (16 случаев), по группе сравнения - 35,6\% (32 случая). Различия по этому показателю были статистически значимыми $(\chi 2=19,80, \mathrm{p}=0,002)$.

Важным показателем, характеризующим успешность остеосинтеза, является продолжительность лечения больных стационарного и амбулаторного. Полученные сравнительные данные представлены на Рисунке 2.

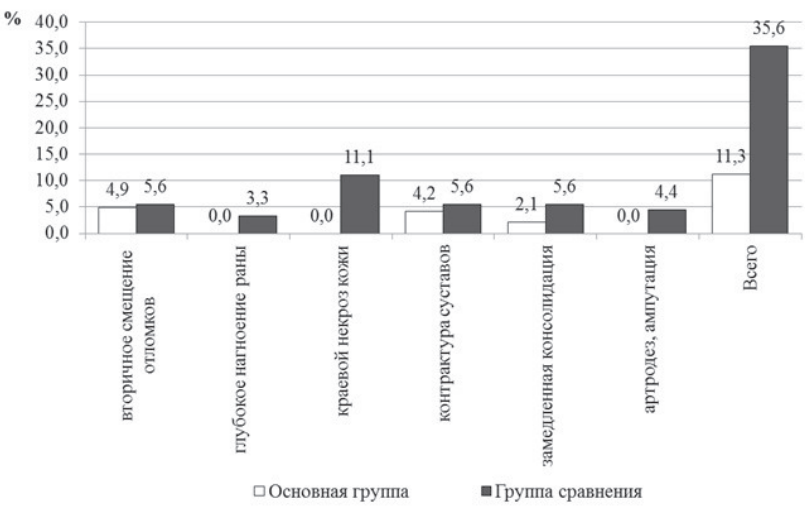

Рисунок 2 - Сравнительная характеристика продолжительности лечения больных основной группы и группы сравнения

Имелись некоторые различия по продолжительности стационарного и амбулаторного лечения больных между группами. Так, в основной группе стационарное лечение оказалось короче в среднем на 2,4 койко-дня (p>0,05), а период амбулаторного лечения - на 6,2 суток ( $>0,05)$. В целом применение методики трансартикулярной фиксации способствовало уменьшению периода лечения на 8,6 суток (также без статистической значимости различий).

Функциональные результаты лечения в сравниваемых группах представлены на Рисунке 3.
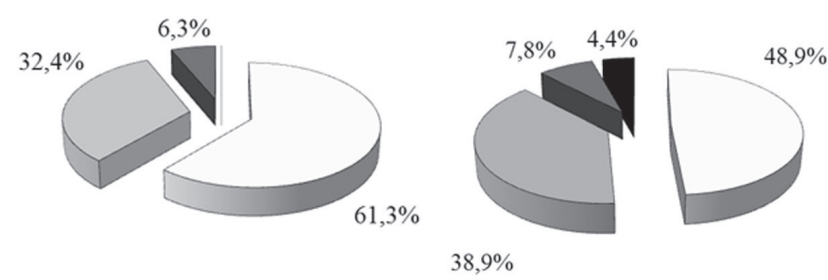

$$
\begin{aligned}
& \square \text { Отлично } \\
& \square \text { Хорошо } \\
& \square \text { Удовлетворительно } \\
& \text { в Неудовлетворительно }
\end{aligned}
$$

Рисунок 3 - Функциональные результаты лечения больных с переломами лодыжек (слева - основная группа, справа группа сравнения)

Как видно на рисунке, отличные результаты были получены несколько чаще в основной группе (на 25,4\% чаще), хотя различия между группами были незначимыми. Вполне сравнимой была частота хороших и удовлетворительных результатов. Неудовлетворительные результаты в виде выполнения артродеза (3 случая) и ампутации (1) наблюдались только в группе сравнения.

Результаты анализа качества жизни у больных основной группы и группы сравнения представлены на Рисунке 4. 

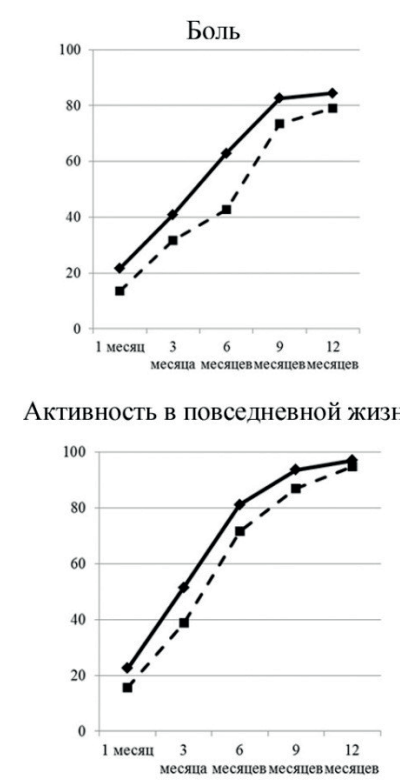

Активность в повседневной жизни

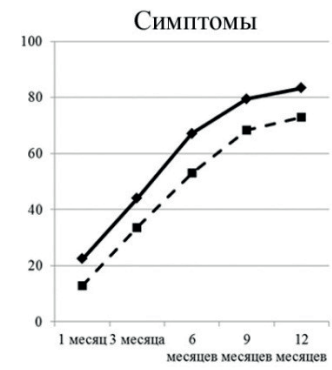

Спорт и отдых

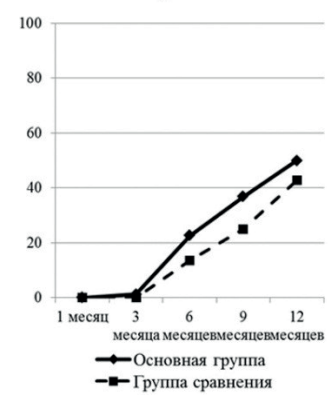

Рисунок 4 - Динамика показателей качества жизни по методике FOAS в зависимости от клинической группы

Определенные по методике FOAS показатели качества жизни в основной группе на всем протяжении исследования превышали таковые в группе сравнения. Значимые различия были получены по шкале «боль» в срок обследования 6 месяцев. Их уровень составил 46,7\% ( $<<0,05)$.

Однако по шкале «симптомы» различия оставались на уровне тенденций на всем протяжении исследования. Также не было существенных различий между группами по шкале «активность в повседневной жизни».

В то же время, более ранняя активизация пациентов при применении разработанной методики заметна по шкале «спорт и отдых», где значимые различия выявлены в срок 6 и 9 месяцев. Они составили, соответственно, $67,4 \%(\mathrm{p}<0,01)$ и $47,9 \%(p<0,05)$.

\section{Обсуждение результатов}

Выбор трансартикулярной фиксации для лечения пациентов с переломами лодыжек, сопровождающимися вывихом стопы, является не случайным. Именно спицевая трансартикулярная фиксация, по мнению специалистов отечественной школы, остается наименее травматичным методом создания стабильного остеосинтеза при данном типе повреждений [9].
В то же время, имеются существенные проблемы применения данного метода, в число которых входит необходимость точного проведения спиц. Опыт показывает, что при их проведении «на глаз», по анатомическим ориентирам, нужное положение достигается далеко не всегда. По нашему опыту, примерно в $30 \%$ случаев одну или несколько спиц приходится проводить повторно после рентгеновского контроля их положения. Это связано с индивидуальными особенностями пациентов и нарушениями ориентиров, связанными с наличием повреждения [10].

Данное осложнение увеличивает травматичность и продолжительность вмешательства, требует проведения дополнительных рентгеновских исследований. Увеличивается тяжесть артроза голеностопного сустава $[11,12]$. Поэтому гарантированно точное проведение спиц является существенным аспектом улучшения качества вмешательства в целом.

У большинства пациентов основной группы (97 человек - 68,3\%) проведение спиц осуществлялось с использованием разработанного устройства, что позволило избежать ошибок и связанной с ними травматизации.

В целом использование способа трансартикулярной фиксации в нашем исследовании оказалось целесообразным и дало лучшие результаты, чем открытые вмешательства как в отношении клинического течения, так и качества жизни пациентов.

\section{Выводы}

1. Применение методики трансартикулярной фиксации в лечении переломов лодыжек с вывихом стопы обеспечивает значимо меньшую частоту различных осложнений по сравнению с открытыми способами (11,3\% против $35,6 \%)$.

2. При применении трансартикулярной фиксации получены лучшие функциональные результаты в сравнении с группой использования открытых способов (отличные - $61,3 \%$ против $48,9 \%$, хорошие $32,4 \%$ и $38,9 \%$, удовлетворительные - $6,3 \%$ и 7,8\% соответственно, неудовлетворительных результатов не было против 4,4\% в группе сравнения).

3. Более высокие показатели качества жизни были определены при применении трансартикулярной фиксации по шкалам «боль» и «спорт и отдых» в сроки 6-9 месяцев с момента получения травмы.

Disclosures: There is no conflict of interest for all authors.

\section{Список литературы}

1. Shukurov Je.M. Sovremennye aspekty lechenija bol'nyh s mnozhestvennymi perelomami kostej nizhnih konechnostej (Modern aspects of treatment of patients with multiple fractures of the bones of lower extremities) [In Russian]. Genij ortopedii. 2014; 3: 89-93.

2. Sitnik A.A., Beleckij A. V. Minimal'no-invazivnyj osteosintez plastinami pri perelomah dlinnyh trubchatyh kostej (Minimally invasive osteosynthesis by plates in fractures of long tubular bones) [In Russian]. Med. novosti. 2009; 7(175): 15-18.

3. Klimovickij V.G., Chernysh V.Ju., Hatem Lafi, Tancjura V.P. Analiz kriteriev vybora sposoba osteosinteza vnesustavnyh perelomov kostej goleni (retrospektivnoe issledovanie) (Analysis of selection criteria for the method of osteosynthesis of extraarticular fractures of the shin bone (retrospective study)) [In Russian]. Travma [Elektronnyj resurs]: 2013; 14(1).

4. Rusanov A.G., Stadnikov V.V. Al'ternativnyj variant tehnologii chreskostnogo osteosinteza perelomov goleni (Alternative version of the technology of transosseous osteosynthesis of the lower leg) [In Russian]. Saratov. nauch.-med. zhurn. 2008; 22(4): 88-89.

5. Karasev A.G. Chreskostnyj osteosintez po Ilizarovu pri lechenii bol'nyh s mnozhestvennymi perelomami kostej konechnostej. Sbornik tezisov dokladov 9 s\#ezda travmatologov-ortopedov Rossii (Transosseous osteosynthesis by Ilizarov in the treatment of patients with multiple fractures of limb bones) [In Russian]. Saratov, 2010; 1: 162. 
6. Kotel'nikov G.P., Mironov S.P. (red.) Travmatologija: nacional'noe rukovodstvo (Traumatology: national guideline) [In Russian]. M.: GEOTAR-Media; 2008: 808 s.

7. Li A., Wei Z., Ding H., Tang H., Liu Y., Shi J. et al. Minimally invasive percutaneous plates versus conventional fixation techniques for distal tibial fractures: A meta-analysis. Int J Surg. 2017; 38: 52-60. doi: 10.1016/j.ijsu.2016.12.028.

8. Viskarra Mollinedo Je., Zimina Je.V., Turina S.A., Jarygin N.V. Validizacija shkal i voprosnikov dlja ocenki funkcional'nogo sostojanija i kachestva zhizni pacientov s perelomovyvihami golenostopnogo sustava (Validation of scales and questionnaires for assessing the functional state and quality of life of patients with ankle fractures) [In Russian]. Rossijskie medicinskie vesti. 2011; XVI(2): 61-71.

9. Korzun O.A. Hirurgicheskoe lechenie perelomov lodyzhek s podvyvihom i vyvihom stopy (Surgical treatment of ankle fractures with subluxation and dislocation of the foot): avtoref. dis. ... kand. med. nauk. [In Russian]. Minsk, 2008: 19 s.

10. Grishin V.N. Lechenie i profilaktika oslozhnenij pri svezhih i zastarelyh vnutrisustavnyh povrezhdenijah distal'nogo otdela goleni (Treatment and prevention of complications with fresh and chronic intraarticular injuries of the distal calf): avtoref. diss ... dokt.med.nauk. [In Russian]. Moskva, 2006: 38 s.

11. Kaplan A.V., Abel'cev N.P. Transartikuljarnaja fiksacija stopy i zakrytyj osteosintez spicami pri lechenii perelomov lodyzhek so smeshheniem otlomkov i podvyvihami stopy: metodich. rekomendacii (Transarticular fixation of the foot and closed osteosynthesis with spokes in the treatment of fractures of the ankles with displacement of fragments and subluxations of the foot: methodical recommendations) [In Russian]. M., 1984: 9 s.

12. Gorbatov R.O., Pavlov D.V., Malyshev E.E. Sovremennoe operativnoe lechenie perelomov lodyzhek i ih posledstvij (obzor) (Modern surgical treatment of ankle fractures and their consequences (review)) [In Russian]. Sovremennye tehnologii $v$ medicine. 2015; 7(2): 153-167.

How to cite this article: Askar Serikbaev, Almas Dyusupov, Asanali Seitkabylov. Clinical results of the application of the transarticular fixation technique with the use of the device for the exact spokes conduction for fractures of the ankles with foot dislocation. [in Russian]. J Clin Med Kaz. 2018; 2(48):47-51 